\title{
Meloxicam Impact on Blood Plasma Cortisol Levels in Dystocia Affected Bovines
}

\section{Umed Singh Mehra ${ }^{1 *}$, S. C. Arya ${ }^{2}$, Anupama Deora ${ }^{3}$, Ravidutt Rai ${ }^{2}$, Rajendra Yadav ${ }^{4}$, Pankaj Kumar ${ }^{5}$ and R. P. Diwakar ${ }^{6}$}

${ }^{1}$ Department of Animal Husbandry and Dairying, Haryana, India

${ }^{2}$ Department of Veterinary Gynaecology and Obstetrics, LUVAS, Hisar-125004, Haryana, India

${ }^{3}$ Department of Veterinary Microbiology and Biotechnology, College of Veterinary and Animal Science Rajasthan University of Veterinary and Animal Sciences, Bikaner - 334 001, Rajasthan, India

${ }^{4}$ Regional Referral Veterinary Diagnostic and Extension Centre (RVDEC), Mahendergarh, India

${ }^{5}$ Department of Veterinary Public Health and Epidemiology, LUVAS, Hisar-125004, Haryana, India

${ }^{6}$ Department of Veterinary Microbiology, C.V.Sc\&A.H., N.D.U.A\&T., Kumarganj, Faizabad (U.P), India

*Corresponding author

\section{A B S T R A C T}

\begin{tabular}{|l|l|l|l|l|l}
\hline Keywords & $\begin{array}{l}\text { Cortisol is often called the "stress hormone" because of its connection to the stress } \\
\text { response, however, cortisol is much more than just a hormone released during stress. } \\
\text { caesarean operation }\end{array}$ & $\begin{array}{l}\text { Parturition, although a physiological process, is a great stress for Dam. So In our studywe } \\
\text { tried to evaluate impact of meloxicam on blood plasma cortisol levels in dystocia affected } \\
\text { bovines. Cortisol higher levels were maintained even after delivery in surgically handled } \\
\text { cases and in buffaloes without preemptive administration of meloxicam. The cortisol } \\
\text { Article Info }\end{array}$ & $\begin{array}{l}\text { levels were found to be significantly }(\mathrm{P}<0.05) \text { elevated at the time of presentation in } \\
\text { buffaloes which subsequently expired after obstetrical manipulation or caesarean } \\
\text { operation. }\end{array}$ \\
\hline $\begin{array}{l}\text { Accepted: } \\
\text { Available Online } 2018 \\
10 \text { June 2018 }\end{array}$ &
\end{tabular}

\section{Introduction}

Plasma glucocorticoids has been considered as a reliable end point for evaluating intensity of stress and of subsequent adaptation (Stephens, 1980; Stott, 1981). Cortisol is a hormone, which is mainly released at times of stress and has many important functions in animal body. Cortisol is a steroid hormone, in the glucocorticoid class of hormones. When used as a medication, it is known as hydrocortisone. Parturition, although a physiological process, is a great stress for Dam. Cortisol is one of the most important member of the steroids from 
the stress point of view. The corticosteroid concentration rises in the plasma of the parturient cows at term and this dramatic rise is followed by sudden fall immediately after parturition (Adams and Wagner, 1970, Smith et al., 1973 Hudson et al., 1976, Hunter et al., 1977; Prakash and Madan, 1985).

Prabhakar et al., (2002) assessed the degree of stress due to occurrence of dystocia and its correction by fetotomy and caesarean section by monitoring cortisol levels in dystocia affected buffaloes. Cortisol concentrations in dystocia-affected buffaloes were 3 to 4 folds higher than that in the normally calving counter parts. The cortisol levels further increased during manoeuvring as compared to pre manoeuvring levels. The buffaloes, which ultimately died following manoeuvring, had prolonged elevated cortisol levels as compared to their surviving counterparts.

Although there are several studies on the effect of dystocia on uterine infections, periparturient disorders, milk production, and newborn survival (Jeffrey and Edward; 1988), limited studies looking at the effect of dystocia on blood biochemical parameters in Buffaloes are available. In addition, the interactions among plasma concentrations of cortisol in relation to the difficult labour have not been well established. Therefore, in the present study, we planned to study the effects of dystocia on plasma cortisol concentrations in dystocia affected Buffaloes.

\section{Materials and Methods}

The present investigation was carried out on 41 dystocia affected buffaloes brought to the teaching veterinary clinics, CCS HAU, Hisar for treatment. Before attempting to relieve the dystocia, a complete history of the case with regard to parity, stage of gestation, duration of problem and previous handling of the case by the field staff/laymen, was obtained from the owner. Thorough general and systemic examination of each case was performed. Rectal temperature, respiration rate, heart rate and rumen motility of every animal was recorded on arrival and subsequently at 2 and 24 hours post treatment.

The nature and cause of dystocia was detemined on the basis of systemic examination and depending upon the cause of difficulty in birth and the duration and pervious handling of the case, obstetrical management was carried out.

All the animals received routine supportive therapy consisting of parentral antibiotics, dexamethasone, fluid therapy, hemostatic, uterine stimulants and intrauterine antiseptics post-delivery of the foetus.

\section{Experimental groups}

The cases of dystocia were randomly assigned to two groups based on different pre-operative treatment schedule Group I comprised of 19 buffaloes in which mutation/forced extraction or caesarean section was performed to relieve dystocia followed by usual post-operative care of the dam whereas Group II consisted of 22 cases in which obstetrical operation was preceded by $\mathrm{I} / \mathrm{M}$ administration of meloxicam @ $0.5 \mathrm{mg} / \mathrm{kg} \quad$ B.Wt., 15 minutes prior to surgery / manipulative delivery.

These groups were further subdivided for the purpose of analysis of data and interpretation depending upon the obstetrical operation and survival following treatment.

\section{Sub grouping on the basis of obstetrical operation}

Group- $\mathrm{I}_{\mathrm{A}}$ consisted of 8 buffaloes in which dystocia was relieved by non-surgical techniques and without pre-emptive administration of meloxicam. 
Group- $\mathrm{I}_{\mathrm{B}}$ comprised of 11 buffaloes in which foetus was removed by laparohysterotomy without administration of meloxicam prior to surgery.

Group $\mathrm{II}_{\mathrm{A}}$ included 8 meloxicam administered dystocia affected buffaloes treated non surgically.

Group $\mathrm{II}_{\mathrm{B}}$ was comprised of 14 caesarean operated buffaloes treated preemptively with meloxicam.

Sub grouping on the basis of survival of dam following obstetrical management

Group S consisted of 24 buffaloes which survived following treatment.

Group D included 17 buffaloes which died during or after obstetrical operation.

Groups $S_{\text {I }}$ and $S_{\text {II }}$ consisted of 13 and 11 buffaloes respectively which survived without/with pre emptive administration of meloxicam.

Groups $D_{\text {I }}$ and $D_{\text {II }}$ were composed of six and 11 buffaloes respectively which died following obstetrical intervention without/with administration of meloxicam.

Groups $\mathrm{S}_{\mathrm{B}}$ and $\mathrm{D}_{\mathrm{B}}$ included 12 and 13 caesarean operated buffaloes respectively which survived or died following operation. Irrespective of treatment with Meloxicam.

\section{Sampling Schedule}

Jugular blood samples were collected by standard venipuncture technique from all the cases before treatment (Ohour) and then at 2 hours and 24 hours post-maneuovering. Two $\mathrm{ml}$ of blood was drawn in vials containing sodium oxalate for hematological investigations and $20 \mathrm{ml}$ was collected in heparinised glass tubes. Five $\mathrm{ml}$ of blood was kept in refrigerator for histamine assay and the remaining blood was centrifuged at $3000 \mathrm{rpm}$ for 10 minutes for separation of plasma. Blood plasma was stored at $-20^{\circ} \mathrm{C}$ for subsequent blood biochemical and endocrinological studies.

\section{Hormone Estimation}

Blood plasma cortisol levels were estimated by implying solid phase Radio immuno assay technique using Gamma Coat ${ }^{125 \mathrm{I}}$ RIA Kits supplied by Diasorin Inc. Minnesota U.S.A. The procedure followed for assay was as suggested by the manufacturer of the Kit.

\section{Performance Data of the Kit}

\section{Sensitivity}

The minimal detectable concentration (sensitivity) of the kit used in the present study was reported as $0.21 \mathrm{ug} / \mathrm{dl}$.

\section{Specificity}

The data on cross-reactivity of the antiserum used in the kit has been depicted in AnnexureI. The antiserum had very low cross reactivity to compounds other than cortisol.

\section{Precision}

The intra-run and inter-run Precision was determined by the manufacturer on the basis of 20simultaneous assays per serum sample for the former or 20 separate runs for the latter and observed to be 6.6-7.7 percent and 8.8 to 9.8 percent respectively.

\section{Survivability / Recovery of the Animal}

The cases were followed and data was collected on recovery and survival of dam following treatment by interaction with the 
owner of the animal in order to correlate the observations on different parameters studied with survivability to arrive at possible prognostic indices.

\section{Statistical analysis}

The data was analyzed statistically using Duncan's Multiple Range test (Duncan 1955).

\section{Results and Discussion}

The circulating cortisol concentrations in different groups of dystocia affected buffaloes in the present study have been depicted in Table 40. Pre emptive administration of meloxicam in dystocia affected buffaloes prior to obstetrical intervention had no influence on the circulating plasma cortisol levels. Significant difference was not recorded in cortisol concentrations among different intervals in either meloxicam treated or untreated buffaloes and also between the two groups (Meloxicam treated v/s untreated). Wide individual variation was reflected in blood plasma cortisol concentration in all the groups.

No specific trend was recorded in post treatment levels of circulating cortisol. The levels at 2 and 24 hours post treatment were found to be significantly $(\mathrm{P}<0.05)$ higher in caesarean operated buffaloes when compared with the non-surgically treated buffaloes without preemptive administration of meloxicam (Table 1). However, there was no significant difference in plasma cortisol concentration between surgically and nonsurgically handled dystocia cases when meloxicam was administered prior to obstetrical manipulation.

The cortisol levels were found to be significantly $(\mathrm{P}<0.05)$ elevated at the time of presentation in buffaloes which subsequently expired after obstetrical manipulation or caesarean operation (Table 2). These higher levels were maintained even after delivery in surgically handled cases and in buffaloes without preemptive administration of meloxicam. However, significant difference was not observed in cortisol concentration of meloxicam treated animals which survived or died following obstetrical management.

\section{Survivability V/S treatment}

The data on survival of dystocia affected buffaloes following preemptive administration of meloxicam has been shown in table 4. Only one half of the buffaloes suffering from difficulty in birth survived when the buffaloes had been administered meloxicam intramuscularly prior to handling of dystocia. The survival rate of the dam was much better $(68.42 \%)$ when meloxicam was not administered to the dystocia affected buffaloes.

Higher percentage of buffaloes with dystocia survived following treatment $(68.75 \%)$ when difficult birth was managed by non-surgical manoeuvring as compared to the buffaloes in which foetus was delivered by laparohysterotomy. Only $52 \%$ of the caesarean operated buffaloes survived in the present investigation (Table 3). Overall, 24 of the 41 cases treated in this study could survive the obstetrical management of dystocia irrespective of the treatment adopted or procedure followed by the relief of dystocia (Table 3).

Plasma cortisol concentration in dystocia affected buffaloes were observed to be highly elevated as compared to the levels reported by other workers (Dahiya, 1998, Mehta et al., 1991) in normal parturient buffaloes. Similar observation have been recorded earlier by Manju (1984), Siddiquee (1988), Ghuman (1995) and Prabhakar et al., (1999b) in cases of uterine torsion/dystocia in buffaloes. 
Table.1 Effect of Obstetrical operation on plasma Cortisol concentration in Dystocia affected Buffaloes

\begin{tabular}{|l|c|c|c|}
\hline \multirow{2}{*}{ Group } & \multicolumn{3}{|c|}{ Sampling interval Cortisol $(\mathbf{n g} / \mathbf{m l})$} \\
\hline I A $(\mathbf{n = 8})$ & 0 hour & 2 hours & 24 hours \\
\hline I B $(\mathbf{n = 1 1})$ & $21.812 \pm 3.620$ & $20.147 \pm 5.029$ & $\mathbf{1 9 . 9 7 5} \pm 4.202$ \\
\hline II A $(\mathbf{n = 8})$ & $31.409 \pm 3.656$ & $32.600 \pm 8.073 *$ & $\mathbf{2 6 . 6 3 6 \pm 7 . 1 8 9 *}$ \\
\hline II B $(\mathbf{n = 1 4})$ & $19.687 \pm 5.802$ & $25.687 \pm 7.850$ & $\mathbf{3 0 . 3 0 0 \pm 7 . 3 9 1}$ \\
\hline
\end{tabular}

* Significantly $(\mathrm{P}<0.05)$ different between groups at same interval

Table.2 Observation on plasma Cortisol concentration and survivability in different groups of Dystocia affected buffaloes

\begin{tabular}{|c|c|c|c|}
\hline \multirow[t]{2}{*}{ Group } & \multicolumn{3}{|c|}{ Sampling interval Cortisol (ng / ml) } \\
\hline & 0 hour & 2 hours & 24 hours \\
\hline$S(n=24)$ & $20.70 \pm 2.177$ & $23.195 \pm 4.244$ & $19.783 \pm 2.58$ \\
\hline $\mathrm{D}(\mathrm{n}=17)$ & $28.852 \pm 3.74$ & $29.893 \pm 4.804$ & $27.273 \pm 5.620$ \\
\hline S I (n=13) & $22.30 \pm 2.51$ & $21.43 \pm 6.42$ & $17.061 \pm 2.67$ \\
\hline D I $(n=6)$ & $38.33 \pm 4.43 *$ & $40.16 \pm 6.63$ & $38.50 \pm 11.36$ \\
\hline S II (n=11) & $18.80 \pm 3.76$ & $25.27 \pm 5.57$ & $23.00 \pm 4.641$ \\
\hline D II $(n=11)$ & $23.68 \pm 4.65$ & $23.73 \pm 5.97$ & $19.78 \pm 4.56$ \\
\hline S B $(n=12)$ & $18.358 \pm 2.585$ & $22.00 \pm 6.668$ & $15.41 \pm 1.932$ \\
\hline D B $(n=13)$ & $33.461 \pm 3.617 * *$ & $33.400 \pm 5.563$ & $28.083 \pm 6.624$ \\
\hline
\end{tabular}

* Significantly $(\mathrm{P}<0.05)$ different between groups at same interval

Table.3 Effect of obstetrical operation on survival of dystocia affected buffaloes

\begin{tabular}{|l|}
\hline Obstetrical operation \\
\hline Caesarean operation (25) \\
\hline Non-surgically treated \\
\hline Total (41) \\
\hline
\end{tabular}

No. of animals

\section{Survived}

$13(52 \%)$

$11(68.75 \%)$

$24(58.53 \%)$

\section{Dead}

$12(48 \%)$

$5(31.25 \%)$

$17(41.46 \%)$

Table.4 Effect of preemptive administration of meloxicam on survival of Dystocia affected buffaloes

\begin{tabular}{|l|}
\hline Group \\
\hline Meloxicam treated (22) \\
\hline Meloxicam untreated (19) \\
\hline Total (41) \\
\hline
\end{tabular}

\begin{tabular}{|c|}
\hline No. of a \\
\hline Survived \\
\hline $11(50 \%)$ \\
\hline $13(68.42 \%)$ \\
\hline $24(58.53 \%)$ \\
\hline
\end{tabular}

\begin{tabular}{|c|}
\hline animals \\
\hline $11(50 \%)$ \\
\hline $6(31.58 \%)$ \\
\hline $17(41.47 \%)$ \\
\hline
\end{tabular}


The elevated concentration of cortisol in dystocia affected buffaloes could be due to stress of dystocia which stimulated adrenal cortex leading to hypercortisolaemia (Manju et al., 1985, Prabhakar, 1995). The variation observed in the cortisol levels in different buffaloes in the present study may be attributed to the variation in individual sensitivity to stress. The high levels of plasma cortisol were maintained upto 24 hours post treatment. Various workers have reported the maintenance of higher levels for periods ranging from day 1 to day 5 post treatment in buffaloes affected with torsion of uterus (Siddiquee, 1988; Manju, 1984; Dahiya, 1998).

Preemptive administration of meloxicam in dystocia affected buffaloes had no influence on the circulating plasma cortisol levels. No such study has been carried out by any other worker in large ruminants. However, Mondal et al., (2006) while investigating the postoperative analgestic effects of different NSAIDS in bitches undergoing ovariohysterectomy, recorded no significant difference in serum cortisol levels in ovariohysterectomised bitches receiving meloxicam@2 mg/kg I/M after completion of surgery. Contrary to this, Fazili (2005) reported significant decline in plasma cortisol concentration within 20 hours of management of fracture in dogs administered meloxicam or rofecoxib prior to surgery. Different analgesics such as Ketamine, pethidine, Ketoprofen and tramadol have been shown to have a suppressive effect on post-operative cortisol response in dogs (Raj et al., 2002; Mondal et al., 2006). Whether meloxicam administration is equally effective in pain management in large ruminants as in canines needs further investigation.

Post treatment plasma cortisol concentrations were significantly higher in caesarean operated buffaloes than the buffaloes in which dystocia was handled non surgically. This is in tune with the observation of Heuwiesser et al., (1987) who reported significantly higher glucocorticoid concentrations in cows on which caesarean section had been carried out than those whose calves were extracted by traction. Higher cortisol levels after caesarean section in buffaloes under report is reflective of higher tissue trauma and pain in these animals. Rise in cortisol has been suggested to be in proportion to severity of the tissue trauma (Schmidt and Brooker, 1982). Marked increase in cortisol concentration have been reported after variety of surgical procedures in dogs and cats (Kyles et al., 1998and Cambridge et al., 2000). According to Tsuji et al., (1983) and Robertson (2003) the level of increase depends upon the magnitude of operative stress.

Buffaloes which could not survive following caesarean section were having significantly higher plasma cortisol concentration at the time of presentation of case and these higher concentration were maintained upto 24 hours post operatively. This indicates that the animals which subsequently died were highly stressed even before the operation was carried out.

Similar observations have been made by Ghuman (1995) in buffaloes with uterine torsion in which detorsion was done by rolling the dam. He concluded that prolonged elevation of cortisol concentration were associated with death of the affected animals. Prabhakar et al., (2002) while assessing the degree of stress in buffaloes with dystocia maintained that the buffaloes that ultimately died following manoeuvring had prolonged elevated cortisol levels as compared to their surviving counterparts. The monitoring of peripheral cortisol levels particularly the pretreatment concentration may serve as useful index of stress and prognosis in dystocia affected buffaloes. 
Nearly fifty percent of the dystocia affected buffaloes survived following caesarean operation in the present investigation. The survival rate following caesarean section in the present investigation is less than that reported by Luthra (1996) and Luthra and Khar (1999) but matches well with the observations of Prabhakar et al., (1997) and Matharu and Prabhakar (2001). The success rate of caesarean section is lower in buffaloes as compared to cows. Frazer et al., (1996) and Schonfelder et al., (2003) reported that 78\% and $80 \%$ of cows affected with uterine torsion and corrected by caesarean section survived. Thirty four per cent of the animals operated upon for treatment of uterine torsion by Sharma et al., (1995) died during or immediately after surgery.

Several factors influence the success rate of caesarean operation in animals with difficult birth. The most important of these are the duration of dystocia and the previous handling of the case. As the interval between the onset of first stage of parturition and the operation increased. The survival rate decreased (Singh and Dhaliwal, 1998). A drastic reduction in success rate of caesarean section has been recorded by Murthy et al., (1999) as the duration of dystocia increased from 24 to 72 hours (100\% v/s 25\%). Matharu and Prabhakar (2001) obtained lower survival rate when the buffaloes were subjected to caesarean section either due to failure of detorsion or failure of cervical dilation $(50.0 \%)$ as compared to those where caesarean section was performed directly without attempted detorsion.

All the cases referred to the vety. Clinics and included and most of these were the delayed cases. This may account for only fifty two per cent of the buffaloes surviving caesarean operation. The higher percentage of buffaloes surviving after obstetrical management of dystocia when non-surgical methods were employed as compared to the C.S. should be because of cumulative stress of dystocia and surgery in the later. Caesarean section has been found to be highly stressful as reflected by plasma cortisol levels (Prabhakar, 1995; Dahiya, 1998). Higher cortisol levels in caesarean operated buffaloes than the nonsurgically handled dyctocia in the present study supports the view that caesarean operation adds stress of an already stressed individual and leads to reduction in chances of survival following obstetrical manoeuvring.

\section{References}

Adams, W.M. and Wagner, W.C. (1970). The role of corticoids in parturition.Biol. Reprod.3: 223.

Cambridge, A.J., Tobias, K.M., Newberry, R.C. and Sarkar, D.K. (2000).Subjective and objective measurements of postoperative pain in cats.J. Am. Vet. Med. Assoc. 217: 685-690.

Dahiya, N.K. (1998). Studies on post caesarian rumen function and the use of b-adrenergic agonists in buffaloes with dystocia. M.V.Sc. Thesis Haryana Agric. Univ., Hisar, India.

Fazili. (2005). Studies on comparative evaluation of meloxicam and rofecoxib in management of postoperative pain in canine orthopaedic cases.Ph.D. Dissertation, Chaudhary Charan Singh Haryana Agricultural University, Hisar, India.

Frazer, G.S.; Perkins, N.R.; Constable, P.D. (1996). Bovine uterine torsion: 164 Hospital referral cases. Theriogenology46: 739-758.

Ghuman, S. Sarvpreet. (1995). Studies on stress of dystocia due to uterine torsion in buffaloes. M.V.Sc. Thesis, Punjab Agric. Univ., Ludhiana. India. 
Heuwiesser, W., Hartig, U., Offeney, F. And Grunert, E. (1987). Significance of gluco-corticoids as a parameter of stress in cattle in the peri-parturient period. $J$. Vet. Med. A. 33: 178.

Hudson, S., Mullford, M., Wittlestone, W.G. and Payne, E. (1976).Bovine plasma corticoids during parturition.J. Dairy Sci. 59: 744.

Hunter, J.I., Fairclough, R.J., Peterson, A.J. and Welch, R.A.S. (1977).Fetal and maternal hormonal changes preceeding normal bovine parturition. ActaEndocrinol. 84: 653-662.

Jeffrey, S.S. and Edward O.C. (1988). Reproductive disorders in the periparturient dairy cow. J Dairy. 71: 2572- 2583.

Kyles, A.E., Hardie, E.M., Hansen, B.D. and Papich, M.G. (1998). Comparison of transdermal fentanyl and intramuscular oxymorphone on post-operative behaviour after ovario-hysterectomy in dogs.Res. Vet. Sci. 65: 245-251.

Luthra, R.A. (1996). Survival rate in Buffaloes and cows following caesarean section performed under field conditions. Haryana Vet. 35: 69-71.

Luthra, R.A.; Khar, S.K. (1999).Survival rate following different regimes of treatment in cases of uterine torsion in Buffaloes.Indian Vet.J. 76: 399-402.

Manju, T.S. (1984). Incidence of uterine torsion and associated biochemical changes in buffaloes (Bubalus bubalis). M.V.Sc. Thesis, Haryana Agric. Univ., Hisar, India.

Manju, T.S. and Verma, S.K. (1985).Uterine torsion in buffaloes Incidence.Indian $J$. Anim. Reprod. 6(1): 54-56.

Manju, T.S. Verma, S.K., Gupta, R.C., Mandakhot. V.M. and Krishnaswamy, A. (1985). Profiles of some plasma biochemical constituents associated with uterine torsion and following its correction by laprohysterotomy in buffaloes. Indian J. Anim. Reprod. 6: 57-61.

Matharu, S.S., Prabhakar, S. (2001). Clinical observation and success of treatment of uterine torsion in Buffaloes.Indian $J$. Anim. Repord. 22: 45-48.

Mehta, V.M. Sarvaiya, N.P., Pathak, M.M. Patel, A.V. and Jaiswal, R.S. (1991). Changes in circulating steroid hormonal profile during thirty days postpartum in Surti buffaloes. Indian J. Anim. Sci. 61(5): 532-534.

Mondal, P.; Nandi, S.K.; Ghosh, D. (2006). Evaluation of post-operative analgesia of ketoprofen, Meloxicam and tramadol in bitches undergoing ovariohysterectomy. India J. Animal Sciences.75: 513-515.

Murty, K.K.; Prasad, V.; Murty, P.R.K. (1999). Clinical observations on uterine torsion in Buffaloes.Indian Vet. J. 76: 643-645.

Prabhakar, S. Nanda, A.S. and Ghuman, S.P.S. (2002). Changes in plasma cortisol concentrations as an index of stress due to dystocia and obstetrical manoeuvring in buffaloes.Indian $J$. Anim. Sci. 72: 309-11.

Prabhakar, S.; Dhaliwal, G.S.; Sharma, R.D.; Nanda, A.S. (1997). Success of treatment and dam survival in bovines with precervical uterine torsion. Indian J. Anim. Reprod.18: 121-123.

Prabhakar, S.; Nanda, A.S. and Ghuman, S.P.S. (1999b). A preliminary attempt towards modulation of stress due to obstetrical intervention in buffaloes.Indian J. Anim. Sci. 69(12): 1018-1019.

Prakash, B.S. and Madan, M.L. (1985). Periparturient progesterone and prostaglandin $\mathrm{F}(\mathrm{PGF})$ levels in buffaloes (Bubalus bubalis). Indian J. Anim. Sci. 55(8): 642-646.

Raj, H., Amarpal, Singh, G.R. and Aithal, H.P. (2002). Comparison of preemptive 
analgesia with epidural pethidine and ketamine for the management of postoperative pain in dogs.Indian Vet. $J$. 79: 69-72.

Robertson, S.A. (2003). How do we know if they hurt? Pain assessment in small animals.Vet. Med. 98: 700708.

Schmidt, R.E. and Booker, J. L. (1982). Effects of different surgical stresses on haematological and blood chemistry values in dogs.J. Am. Anim. Hosp. Assoc. 18: 758-762.

Schonfelder, A., Richter, A., Sobiraj, A. (2005). Stages of surgically incorrectable uterine torsion of cows: associations with clinical progress. Tierarztliche-Umschau.60 (4): 199-205.

Sharma, S.P.; Agrawal, K.B.P. and Singh, D.P. (1995). Torsion of gravid uterus and laparohysterotomy in bovines a report on 72 clinical cases. Indian. Vet. J. 72: 1180-1182.

Siddiquee, G.M. (1988). Studies on aetiopathology and therapeutics of uterine torsion in buffaloes. Ph.D.
Dissertation. Punjab Agric. Univ. Ludhiana, India.

Singh, J. and Dhaliwal, G.S. (1998). A retrospective study on survivability and fertility following caesarean section in bovines.Indian J. Anim. Reprod.19: 2123.

Smith, V.G., Edgerton, L.A., Hafs, H.D. and Convey, E.M. (1973). Bovine serum estrogens, progesterone and glucocortiocoids during late pregnancy, parturition and early lactation. J. Anim. Sci. 36(2): 391-396.

Stephens, D.B. (1980). Stress and its measurement in domestic animals. A review of behavioural and physiological studies under field and laboratory situations. Adv. Vet. Sci. Comp. Med. 24: $179-210$.

Stott, G.H. (1981). What is animal stress and how it is measured? J. Anim. Sci. 52: 150-53.

Tsuji, H., Asoh, T., Takeuchi, Y. and Shirasaka, C. (1983). Attenuation of adrenocortical response to upper abdominal surgery with epidural blockade. Br. J. Surg. 70: 122-124.

\section{How to cite this article:}

Umed Singh Mehra, S. C. Arya, Anupama Deora, Ravidutt Rai, Rajendra Yadav, Pankaj Kumar and Diwakar R. P. 2018. Meloxicam Impact on Blood Plasma Cortisol Levels in Dystocia Affected Bovines. Int.J.Curr.Microbiol.App.Sci. 7(06): 3374-3382. doi: https://doi.org/10.20546/ijcmas.2018.706.396 